\title{
Psychosocial Outcomes of Urban African American Adolescents Born to Teenage Mothers ${ }^{1}$
}

\author{
Marc A. Zimmerman, ${ }^{2}$ Lisa Tuttle, Edie Kieffer, Edith Parker, and \\ Cleopatra H. Caldwell
}

University of Michigan, Ann Arbor

\author{
Kenneth I. Maton \\ University of Maryland/Baltimore County
}

This is a study of psychosocial outcomes of adolescents born to teenage mothers. Adolescents' problem behaviors, psychological well-being, social support, school variables, and sexual behaviors are compared across three groupsthose born to mothers 17 or younger, mothers 18-19 years old, and mothers 20 or older. Analyses from two samples of African American adolescents from Maryland $(\mathrm{n}=205)$ and Michigan $(\mathrm{n}=570)$ are reported. The results from both samples indicate that mother's age at birth is unrelated to adolescents' psychosocial outcomes. These two studies add to the limited number of analyses that examine adolescent outcomes for children of teen mothers. The results suggest that efforts to understand social structural determinants of healthy and problematic adolescent development may be more informative than examining the effects of mother's age. They also suggest that teen pregnancy prevention programs may be more effective if they are part of a larger prevention

\footnotetext{
${ }^{1}$ The research reported was funded by the National Institute on Drug Abuse, Grant \# DA04766 (study 1) and Grant \# DA07484 (study 2), and U.S. Department of Justice, Office of Juvenile Justice and Delinquency Prevention Grant \# 87JNCX0010 (study 1). The research reported here does not represent the views or policies of any of the funding agencies. We would like to thank PURA at the University of Michigan-Flint who helped collect the data for this project, the School officials in Baltimore, Maryland, and Flint, Michigan, whose help and support was instrumental for making these studies possible, and most important the young adults who agreed to participate in the research.

${ }^{2}$ To whom correspondence should be addressed at Department of Health Behavior and Health Education, School of Public Health, University of Michigan, Ann Arbor, 48109-2029; e-mail: marcz@umich.edu.
} 
strategy that incorporates social structural change efforts and not only a focus on individual level change.

KEY WORDS: maternal age; African American; psychosocial outcomes; adolescents.

For the past 30 years, national policy makers have raised concerns about the social, economic, and health implications of teenage pregnancy (Alexander \& Guyer, 1993; National Research Council, 1987). Teenage pregnancy is perceived to be detrimental to society because of the billions of dollars spent annually on support services to young mothers and their children, and the corresponding loss of potential labor force productivity (Alexander \& Guyer, 1993). Although several researchers have reported negative physical, health, social, and economic consequences of childbearing on the adolescent mother, especially very young teenage mothers (Furstenberg, Brooks-Gunn, \& Morgan, 1987; Hetchman, 1989; McAnarney \& Hendee, 1989; Scholl \& Hediger, 1993; Scholl, Hediger, Schall, Khoo, \& Fischer, 1994; Spivak \& Weitzman, 1987), fewer investigators have examined the effects of having been a teenage mother on the development of their offspring at adolescence. The negative effects of teenage childbearing on their children is based on the assumption that teenage mothers are generally considered to be immature and unable to provide proper care and nurturing for their children (Panzarine, 1988). Yet, some researchers have failed to support the hypothesis that teenage parents are less competent than older parents (Brooks-Gunn \& Chase-Lansdale, 1995).

Most research on outcomes for children of teenage mothers has focused on child outcomes in infancy, early childhood (0-7 years of age), and preadolescence (8-10 years of age) (Baldwin \& Cain, 1980; Buchholz \& Gol, 1986; Hetchman, 1989; Hofferth, 1987; Hubbs-Tait, Osofsky, Hann, \& Culp, 1994). In addition, most of these studies used data from the $1979 \mathrm{Na}-$ tional Longitudinal Survey of Youth (NLSY), and the subsequent surveys of the children born to the women of the NLSY from 1986-90 (Barratt, 1991; Geronimus, Korenman, \& Hillemeier, 1994; Ketterlinus, Henderson, \& Lamb, 1991; Luster \& Dubow, 1990; for a review and discussion of the Children of the NLSY, see Chase-Lansdale, Mott, Brooks-Gunn, \& Phillips, 1991). The NLSY oversamples minority and poor women, and overrepresents young childbearers, thus providing an excellent opportunity to examine the outcomes of adolescent pregnancy, but the findings are limited to only one sample, select data, and a specific cohort (Chase-Lansdale et al., 1991; Ketterlinus et al., 1991). It is useful to test if findings from population surveys are consistent with more specific, locally relevant samples, and to examine effects for different cohorts of youth. Camp (1996) points out that, in general, research on outcomes for the children of teenage mothers are explained 
by factors other than maternal age, such as socioeconomic status (SES), household composition, maternal education and intelligence, and parenting practices. These results are somewhat consistent for early childhood and adolescent samples. Although somewhat less relevant for this study, socioeconomic disadvantage and lack of prenatal care may be more harmful to infants than young maternal age (Baldwin, 1993; Hetchman, 1989; Kieffer, Mor, \& Alexander, 1996). Investigators have actually found that infants born to African American teenagers have better perinatal outcomes than infants of older African American mothers (Bachrach, Clogg, \& Carver, 1993; Geronimus, 1992, 1996). Kieffer, Alexander, and Mor (1995) reported no effects of maternal age for birth weight or infant mortality among infants of Samoan and Hawaiian mothers. Geronimus et al. (1994) found that any negative effects of teenage mothering on early childhood development disappeared when race, sex of child, age, and birth order were considered. Other researchers also concluded that the differences in infant cognitive development are small, and reveal little functional deviation in infants born to teenage and older mothers (Hofferth, 1987; Ketterlinus et al., 1991).

Furstenberg's longitudinal study of teenage mothers and their children is a primary source of research on the outcomes of adolescent children born to teenage mothers (Brooks-Gunn, Guo, \& Furstenberg, 1993; Furstenberg et al., 1987; Furstenberg \& Harris, 1993; Furstenberg, Hughes, \& Brooks-Gunn, 1993). Furstenberg's study began in 1966 as an evaluation of a health-care program for adolescent mothers at Sinai Hospital in Baltimore. In a 17-year, follow-up of this sample, Furstenberg et al. (1987) first concluded that 296 adolescent children of teenage mothers-most of whom were African American-exhibited "massive school failure" (p. 148), with half having already repeated a grade, and $61 \%$ reporting that they were $\mathrm{C}$ or D grade students. In a subsequent analysis, using 20-year, follow-up data of the same cohort, Furstenberg et al. (1993) reported that factors during the youth's childhood, such as mother's marital history and time spent on public assistance, influenced the youth's educational and economic success to a greater extent than the age of his/her mother. Furstenberg et al. also found that despite early poverty and initial difficulty managing the transition to adulthood, over $60 \%$ of the youths born to teenage mothers, in their sample, overcame these disadvantages as young adults. Most of the African American adolescents born to teenage mothers in Furstenberg's sample completed high school, delayed childbearing, and found employment in their early adult years.

Others have examined outcomes for adolescents born to teenage mothers who were not part of Furstenberg's sample with mixed results (Dubow \& Luster, 1990; East \& Felice, 1990; Fergusson \& Woodward, 1999; Hardy, Astone, Brooks-Gunn, Shapiro, \& Miller, 1998). Dubow and Luster (1990) 
used the NLSY to examine the outcomes of 721 adolescents born to teenage mothers. The adolescents scored within the national average on academic outcomes, but outcomes for behavioral measures were worse than for the general population. When they examined the predictors of the behavioral measures more closely, however, they found mother's age (under 17, or 17 and older) was not predictive of antisocial behaviors. Rather, they found the number of children in the home, maternal self-esteem, and poverty predicted the antisocial behaviors. Similarly, Fergusson and Woodward (1999) found an association between maternal age and negative outcomes for the children, but it was largely explained by other factors such as parenting practices and home environment.

East and Felice (1990) studied 450 mostly White suburban mothers and their 12-year-old children. They found that teenage mothers had lower educational attainment than older mothers, and their adolescent children had more scholastic problems than youths of adult mothers. Hardy et al. (1998) examined outcomes of children born to teenage mothers in a longitudinal study of over 1,500 urban and mostly African American mother/child pairs. They found more negative outcomes among children of teenage mothers including teenage parenthood, distress, antisocial behaviors, and leaving high school before graduation than among those with parents over 20 years of age. These researchers, however, examined only the direct effects of mother's age, and did not study potential mediating factors such as maternal education or parenting practices.

In sum, researchers have found that for non-White, especially African American youth mother's age is generally not directly associated with negative outcomes. Researchers have found a link between poor child outcomes and young maternal age for non-Whites, but these effects largely disappear when other factors such as SES, prepregnancy educational performance, and emotional and cognitive characteristics of teenage mothers are controlled. Investigators have also found that other factors such as parenting competence and shared parent-child activities explain differences in the outcomes between offspring of teen versus adult mothers (Barratt, 1991; Cooley \& Unger, 1991; Dubow \& Luster, 1990; Fergusson \& Woodward, 1999; Furstenberg et al., 1987; Hubbs-Tait et al., 1994; Luster \& Dubow, 1990). Most of the research on the effects of mother's age on children's outcomes is focused on infants and young children. Our understanding of adolescent outcomes, however, is based on fewer studies that typically examine a limited range of outcomes.

This analysis extends previous research by examining adolescent psychosocial and behavioral outcomes for children born to teenage and adult mothers in two samples not included in previous research on this topic. Study 1 includes a sample of 254 low school achieving, urban, African American 
males aged 15-19 years old. Study 2 includes a sample of 571 urban, African American ninth-graders with less than a 3.0 grade-point average, equally divided by sex. The analysis of the effects of maternal age at birth on low school achieving adolescents may be especially useful because (1) they may be at greater risk for negative outcomes than higher achieving youths and (2) the analysis will reduce the effects of school success on the outcomes studied. These studies also extend previous research by providing information on several psychosocial factors such as problem behaviors, social support, psychological well-being, school achievement, and sexual behaviors that are not typically included in the same study. In addition, we included mother's education in our analyses to examine if maternal age was associated with it, and to control for possible spuriousness. A primary goal of this research is to investigate the relationship between maternal age and an expanded range of outcomes among African American, adolescent children born to teenage mothers. Following previous research that focused on nonWhite samples, we hypothesize that African American adolescents born to teenage mothers will not display worse outcomes than youths born to adult mothers.

\section{STUDY 1}

\section{Sample and Procedure}

African American male adolescents from an inner-city community were selected for this study - part of a larger study focused primarily on youths who did not complete high school (Maton \& Zimmerman, 1992). A multimethod sampling procedure was used. Youths were recruited to participate in the study in four ways: (1) mailings to randomly selected youths from school district dropout lists $(n=90 ; 36 \%$ ); (2) recruitment by neighborhood peers paid to enlist youths ( $n=30 ; 12 \%)$; (3) referrals from community programs such as the Urban League $(n=42 ; 17 \%)$; (4) solicitation through media, posters, and flyers $(n=88 ; 35 \%)$. Four cases had missing recruitment information.

The sample consisted of 254 African American male adolescents from an inner city on the eastern coast of the United States. Seventy percent $(n=179)$ left school before graduation. Most of the youths left school in the ninth $(n=61 ; 32 \%)$ and tenth $(n=48 ; 25 \%)$ grades $(\bar{x}=9.6 ; S D=1.27)$. At the time of the interview, youths no longer attending school had been out of school for an average of 10.6 months $(S D=9.40)$. Youths who did not report their mother's age were not included in the study $(n=49)$. The final sample for this study included 205 adolescents. Their mean age was 
16.9 years $(S D=1.25)$. Fifty-one percent of the youth $(n=105)$ lived with their single mothers, $22 \%(n=44)$ lived with both biological parents, $11 \%$ $(n=23)$ lived with their mother and stepfather, and $16 \%(n=33)$ lived with their mother and extended family $(n=33 ; 16 \%)$.

Face-to-face interviews were conducted by nine trained African American $(n=4)$ and White $(n=5)$ male $(n=2)$ and female $(n=7)$ interviewers. Structured interviews and questionnaires were followed by a series of open-ended questions. Participants were informed that all information shared with the researchers was confidential and protected by a federal certificate of confidentiality.

\section{Measures}

\section{Family Variables}

Maternal Age at Birth of Child. Youths were asked to report who they lived with, their relationship to them, and the person's age. Thus, only youths who reported living with their mother and who knew her age were included in the study. Mother's age at birth of the participant was determined by subtracting the participant's age (computed from his/her birth date) from the reported age of participant's mother. The average maternal age at the birth of the participant was 21.8 years $(S D=5.7)$. Mother's age ranged from 12 to 44 years. Table I reports the frequency (and percentage) for mother's age. Youths were assigned to one of three groups: (1) mother's age was 17 years or less at the time of participant's birth $(n=39 ; 19 \%) ;(2)$ mother's age was 18 or 19 years at the time of participant's birth $(n=38 ; 19 \%)$; (3) mother's age was 20 years or more at the time of participant's birth $(n=128$; $62 \%)$. Six youths were eliminated from the final analyses because of missing data.

We chose these three categories for maternal age for several reasons. First, 17 years and younger refers to an age group for whom timely school completion remains an issue. Second, most teen pregnancy prevalence statistics are presented for youth under 18. Third, youth under 18 tend to have programs designed especially for them to insure school completion, and to help them develop parenting skills (Geronimus, 1992). Fourth, separating out 18-19 year-olds from those who are 20 and over or under 18 helps to tease apart the consequences of early and late teen parenthood on child development. The 18-19 year-olds are also clearly in a life transitional stage from high school to young adulthood. This transition, in turn, may play a significant role in subsequent life outcomes (Bachman, Wadsworth, O'Malley, Schulenberg, \& Johnston, 1997). We did not distinguish mothers below 17 
Table I. Frequency Table for Mothers' Age for Study 1

\begin{tabular}{ccc}
\hline Mothers' age & Frequency & Percent \\
\hline 12 & 1 & 0.5 \\
14 & 7 & 3.4 \\
15 & 8 & 3.1 \\
16 & 8 & 3.1 \\
17 & 15 & 5.9 \\
18 & 19 & 7.5 \\
19 & 19 & 7.5 \\
20 & 25 & 9.8 \\
21 & 21 & 8.3 \\
22 & 13 & 5.1 \\
23 & 17 & 6.7 \\
24 & 9 & 3.5 \\
25 & 6 & 2.4 \\
26 & 8 & 3.1 \\
28 & 2 & 1.0 \\
29 & 3 & 1.2 \\
30 & 4 & 1.6 \\
31 & 2 & 1.0 \\
32 & 2 & 1.0 \\
33 & 7 & 3.4 \\
34 & 1 & 0.5 \\
36 & 2 & 1.0 \\
37 & 1 & 0.5 \\
39 & 2 & 1.0 \\
40 & 1 & 0.5 \\
43 & 1 & 0.5 \\
44 & 1 & 0.5 \\
\hline
\end{tabular}

in our analyses because the sample size for mother's age below age 16 was too small $(n=16)$.

Mother's Education. Youths were asked to indicate the last year of schooling their mothers completed. They averaged $12.4(S D=2.0)$ years of schooling. Fifty-six youths had missing data.

\section{Psychosocial Outcome Measures}

The outcome measures studied are grouped into three categories: (1) problem behaviors; (2) psychological well-being; and (3) perceived social support. The variables included in each of these categories and their descriptive statistics are presented in Table II.

Problem Behaviors. Three variables were included as problem behaviors: alcohol use, marijuana use, and delinquency. Youths were asked to rate their frequency of use over the past 6 months for alcohol and marijuana use. These items used a rating scale ranging from 0 (not at all) to 6 (more than once a day). Delinquency was measured with four dichotomous items 
Table II. Descriptive Statistics for Dependent Variables Across Groups and Total Sample for Study 1

\begin{tabular}{|c|c|c|c|c|c|}
\hline & & $\begin{array}{c}\leq 17 \\
(n=39)\end{array}$ & $\begin{array}{c}18-19 \\
(n=38)\end{array}$ & $\begin{array}{c}\geq 20 \\
(n=128)\end{array}$ & $\begin{array}{c}\text { Total } \\
(n=205)\end{array}$ \\
\hline \multicolumn{6}{|l|}{ Problem behavior } \\
\hline \multirow[t]{3}{*}{ Alcohol use } & $\bar{x}$ & 0.31 & 0.87 & 0.77 & 0.70 \\
\hline & $S D$ & 0.77 & 1.44 & 1.30 & 1.25 \\
\hline & Skewness & 2.36 & 1.98 & 1.87 & 2.04 \\
\hline \multirow[t]{3}{*}{ Marijuana use } & $\bar{x}$ & 0.74 & 1.50 & 1.15 & 1.14 \\
\hline & $S D$ & 1.31 & 1.97 & 1.72 & 1.71 \\
\hline & Skewness & 1.76 & 1.22 & 1.55 & 1.54 \\
\hline \multirow[t]{3}{*}{ Delinquency } & $\bar{x}$ & 5.81 & 6.11 & 5.65 & 5.76 \\
\hline & $S D$ & 1.60 & 1.49 & 1.48 & 1.50 \\
\hline & Skewness & 0.07 & -0.19 & 0.17 & 0.09 \\
\hline \multicolumn{6}{|c|}{ Psychological well-being } \\
\hline \multirow[t]{3}{*}{ Anxiety } & $\bar{x}$ & 10.76 & 11.16 & 11.12 & 11.04 \\
\hline & $S D$ & 3.09 & 4.08 & 4.44 & 4.14 \\
\hline & Skewness & 0.16 & 0.57 & 1.22 & 1.07 \\
\hline \multirow{3}{*}{ Depression } & $\bar{x}$ & 10.38 & 11.26 & 10.56 & 10.66 \\
\hline & $S D$ & 3.65 & 4.81 & 4.49 & 4.39 \\
\hline & Skewness & 0.57 & 1.26 & 1.47 & 1.34 \\
\hline \multirow{3}{*}{ Self-esteem } & $\bar{x}$ & 41.92 & 40.89 & 42.12 & 41.86 \\
\hline & $S D$ & 5.36 & 5.54 & 6.32 & 6.00 \\
\hline & Skewness & -0.40 & -0.77 & -1.21 & -1.01 \\
\hline \multirow[t]{3}{*}{ Life satisfaction } & $\bar{x}$ & 16.00 & 15.73 & 16.22 & 16.09 \\
\hline & $S D$ & 4.88 & 5.26 & 5.49 & 5.32 \\
\hline & Skewness & 0.00 & -0.12 & -0.40 & -0.28 \\
\hline \multicolumn{6}{|l|}{ Social support } \\
\hline \multirow{3}{*}{ Friend support } & $\bar{x}$ & 32.00 & 30.97 & 31.56 & 31.54 \\
\hline & $S D$ & 6.98 & 7.78 & 7.72 & 7.56 \\
\hline & Skewness & -0.12 & -0.14 & -0.18 & -0.17 \\
\hline \multirow[t]{3}{*}{ Parent support } & $\bar{x}$ & 45.54 & 43.59 & 44.28 & 44.40 \\
\hline & $S D$ & 9.00 & 11.27 & 9.39 & 9.66 \\
\hline & Skewness & -0.57 & -0.98 & -1.03 & -0.96 \\
\hline \multirow[t]{3}{*}{ Time with father } & $\bar{x}$ & 7.69 & 7.05 & 9.44 & 8.66 \\
\hline & $S D$ & 12.55 & 11.15 & 15.80 & 14.42 \\
\hline & Skewness & 1.83 & 1.90 & 1.92 & 1.98 \\
\hline
\end{tabular}

asking the youths if they had ever been in trouble with the police, been arrested, appeared before a juvenile court, or been incarcerated in the last year. Delinquency scores could range from 4 (low delinquency) to 8 (high delinquency). The internal reliability of the 4-item delinquency measure is .79 (Zimmerman \& Maton, 1992).

Psychological Well-Being. Psychological well-being includes measures of anxiety, depression, self-esteem, and life satisfaction. Subscales from the Brief Symptom Inventory were used to assess anxiety and depression (Derogatis \& Spencer, 1982). The 6-item anxiety and depression subscales have Cronbach alphas of .62 and .68, respectively. Self-esteem was measured with Rosenberg's (Rosenberg, 1979) 10-item scale. A representative 
item read: "I feel that I'm a person of worth, at least on an equal basis with others." The self-esteem scale has a Cronbach alpha of .75. Life satisfaction was assessed with a 5-item measure that uses a 5-point Likert scale (Diener, Emmons, Larsen, \& Griffin, 1985). Representative items from the life satisfaction scale include "I am satisfied with my life; if I could live my life over, I would change almost nothing." The life satisfaction scale has a Cronbach alpha of .81 in this sample.

Social Support. Perception of social support was measured with three variables: parental support, peer support, and the amount of time spent with father in an average week. Support from parents and friends was assessed using a shortened version of Procidano and Heller's parents and friends scale (Procidano \& Heller, 1983). The shortened parent support scale included 12 of the original 20 items. It has a Cronbach alpha of .91. The shortened friend support scale included 10 of the original 20 items. The Cronbach alpha for the shortened version is .78. Examples of items from the parent support scale include "My parents give me the moral support I need; My parents are good at helping me solve problems." The friend support scale was similar but replaced parent with friend. Both support scales used 5-point Likert formats. Participants were also asked to report how many hours they spend with their father in an average week.

\section{Results}

\section{Mother's Education}

Differences were found across the three mother's age groups for mother's education, $F(2,165)=3.63 ; p<.05$. Duncan paired comparison tests indicated that the 17-year-old and younger mothers had the fewest years of education (11.7 years) and the 18-19-year-old mothers had the most years of education (13.0 years). We also examined correlations of mother's education with all the psychosocial variables and found only self-esteem was correlated with mother's education $(r=.16 ; p<.05)$.

Psychosocial Outcomes. Separate multiple analyses of variance (MANOVA) were computed for the three sets of psychosocial variables problem behaviors, psychological well-being, and social support. No differences were found across the three maternal age groups for problem behaviors, $F(6,390)=1.57 ; n s$, psychological well-being, $F(8,394)=.35 ; n s$, or social support, $F(6,374)=.30 ; n s$. When we compared youths' outcomes for groups defined by mother's age over 20 versus under 20 , the results were the same. We also repeated all the MANOVA analyses described earlier, using number of years of mother's schooling as a covariate and the results remained the same. 


\section{Interviewer Effects}

We found no differences on any outcome for sex of interviewer. Alcohol use was the only difference found for race of interviewer, $t(213)=2.58 ; p<$ .05. Youth interviewed by African American interviewers reported more alcohol use $(\bar{x}=2.46 ; S D=2.55)$ than youth interviewed by Whites $(\bar{x}=$ $1.56 ; S D=2.40)$. No other interviewer race effects were found.

\section{STUDY 2}

\section{Sample and Procedure}

All ninth-grade students from the four public high schools in the second largest school district in a Midwestern state were eligible for the study unless they were (1) diagnosed as being either emotionally impaired or developmentally disabled or (2) had a grade-point average above 3.0. Youths with low grades were selected because this study is part of a larger longitudinal study of high school dropout and substance use. Youth who were emotionally impaired or developmentally disabled were not included in the study because school officials indicated their impairments might make it difficult for them to complete the tasks necessary for the study. The sample included 679 African American youths (80\%), 145 White youths (17\%), and 26 mixed African American and White youths (3\%). This represents over $90 \%$ of the eligible students in the district $(n=911)$.

The sample for this study was selected from the 679 African American youths. Only African American youths were included to make Study 2 more comparable to the sample in Study 1, and because too few White youths had mothers who were teenagers when they were born. One hundred and nine youths were eliminated from the study because they had missing data for their mother's age (mother's age was determined in the same way as in Study 1). The final sample for this study included 570 male and female adolescents. Youths in the final sample had a mean age of 14.6 years $(S D=$ $.66)$. Forty-six percent $(n=266)$ of the youth lived with their single mother, $30 \%(n=170)$ lived with both biological parents, $12 \%(n=68)$ lived with their mother and stepfather, and $12 \%(n=69)$ lived with their mother and extended family.

Face-to-face interviews were conducted by 12 trained African American and White male and female interviewers. Interviewers and students were not matched on sex or race. All students were called from their regular classrooms and taken to select areas within the school. Interviews lasted for 50-60 min. When the face-to-face portion of the interview was 
completed, students were asked to complete a self-administered series of questions about their alcohol and substance use, and sexual behaviors.

\section{Measures}

\section{Family Variables}

Maternal Age at Birth of Child. Mother's age at birth of participant was determined in the same manner as in Study 1, using the same set of questions. The average maternal age at birth was 23.5 years $(S D=5.2)$. Mother's age ranged from 13-42 years. Table III reports the frequency (and percent) for mother's age. Youths were assigned to three groups based upon mother's age at the time of the participant's birth: (1) 17 years or less $(n=64 ; 11 \%)$; (2) 18 and 19 years old ( $n=79 ; 14 \%)$; (3) 20 years or more $(n=427 ; 75 \%)$. Two youths were eliminated from the final analyses because of missing data on this variable.

Table III. Frequency Table for Mothers' Age for Study 2

\begin{tabular}{ccc}
\hline Mothers' age & Frequency & Percent \\
\hline 13 & 2 & 0.4 \\
14 & 3 & 0.5 \\
15 & 11 & 1.9 \\
16 & 19 & 3.3 \\
17 & 29 & 5.1 \\
18 & 36 & 6.3 \\
19 & 43 & 7.5 \\
20 & 37 & 6.5 \\
21 & 43 & 7.5 \\
22 & 45 & 7.9 \\
23 & 47 & 8.2 \\
24 & 38 & 6.7 \\
25 & 27 & 4.7 \\
26 & 39 & 6.8 \\
27 & 31 & 5.4 \\
28 & 27 & 4.7 \\
29 & 22 & 3.9 \\
30 & 17 & 3.0 \\
31 & 12 & 2.1 \\
32 & 10 & 1.8 \\
33 & 6 & 1.1 \\
34 & 8 & 1.4 \\
35 & 6 & 1.1 \\
36 & 3 & 0.5 \\
37 & 4 & 0.7 \\
38 & 3 & 0.5 \\
42 & 2 & 0.4 \\
\hline
\end{tabular}


Mother's Education. Participants were asked to indicate the highest level of schooling their mothers had completed using seven categories: (1) completed grade school or less; (2) some high school; (3) completed high school; (4) vocation or trade school; (5) some college; (6) completed college; (7) postcollege work or degree. Thirty-seven percent of the youths reported that their mothers completed high school and $29 \%$ said their mothers completed some college.

\section{Outcome Measures}

The outcome measures studied were grouped into five categories: (1) problem behaviors; (2) psychological well-being; (3) social support; (4) school outcomes; (5) sexual behavior. The variables included in each of these categories and their means, standard deviation, and skewness are presented in Tables IV and V.

Problem Behaviors. Four variables were included as problem behaviors: alcohol use, marijuana use, nonviolent delinquency, and violent behavior. Alcohol use was measured by the sum of $z$ scores from four self-report items using a yes-no and a 7-point Likert format scale ranging from 1 (never) to 7 (40+times). Youths were asked, "Have you ever had any beer, wine, or liquor to drink (yes/no); How many times have you had alcoholic beverages to drink: in your lifetime, during the last 12 months, and during the last 30 days." Marijuana use was measured by the sum of $z$ scores from three selfreport items, using a 7-point Likert scale ranging from 1 (never) to 7 (40+ times). Students were asked, "How many times have you used marijuana or hashish: in your lifetime; during the last 12 months; and during the last 30 days." The Cronbach alpha for alcohol and marijuana use were .85 and .90 , respectively. Nonviolent delinquency was assessed by how often (1-no times; $5-3+$ times) in the last year youths had engaged in any of 17 behaviors such as property theft, property damage, and sale of illegal drugs. The Cronbach alpha for nonviolent delinquency in this sample is .84. Violent behavior was measured with seven items using the same Likert scale. Students were asked how often in the last year they participated in behaviors such as individual or group fighting, striking a person in authority, and carrying weapons. The Cronbach alpha for the violent behavior scale is .73.

Psychological Well-Being. Psychological well-being includes measures of anxiety, depression, self-acceptance, and active coping. The anxiety and depression subscales used in this study are the same measures described in Study 1. In this sample, the anxiety and depression subscales each have Cronbach alphas of .79. Self-acceptance was measured with four items using a 5-point scale from the Bentler Personality Inventory (Stein, Newcomb, \& 
Table IV. Descriptive Statistics for Problem Behaviors, Psychological Well-Being, Social Support, and School Outcomes Across Groups and Total Sample for Study 2

\begin{tabular}{|c|c|c|c|c|c|}
\hline & & $\begin{array}{c}\leq 17 \\
(n=64)\end{array}$ & $\begin{array}{c}18-19 \\
(n=79)\end{array}$ & $\begin{aligned} & \geq 20 \\
(n & =427)\end{aligned}$ & $\begin{array}{c}\text { Total } \\
(n=570)\end{array}$ \\
\hline \multicolumn{6}{|l|}{ Problem behavior } \\
\hline \multirow[t]{3}{*}{ Alcohol use } & $\bar{x}$ & 4.38 & 4.65 & 5.12 & 4.97 \\
\hline & $S D$ & 4.34 & 4.52 & 4.70 & 4.64 \\
\hline & Skewness & 1.52 & 1.12 & 1.21 & 1.23 \\
\hline \multirow[t]{3}{*}{ Marijuana use } & $\bar{x}$ & 5.59 & 4.47 & 4.73 & 4.79 \\
\hline & $S D$ & 5.76 & 4.97 & 5.46 & 5.43 \\
\hline & Skewness & 0.99 & 1.34 & 1.56 & 1.46 \\
\hline \multirow[t]{3}{*}{ Delinquency } & $\bar{x}$ & 1.33 & 1.25 & 1.32 & 1.31 \\
\hline & $S D$ & 0.42 & 0.37 & 0.53 & 0.50 \\
\hline & Skewness & 1.39 & 2.23 & 3.20 & 3.10 \\
\hline \multirow[t]{3}{*}{ Violent behavior } & $\bar{x}$ & 1.46 & 1.29 & 1.35 & 1.35 \\
\hline & $S D$ & 0.52 & 0.39 & 0.54 & 0.52 \\
\hline & Skewness & 1.06 & 1.58 & 2.36 & 2.19 \\
\hline \multicolumn{6}{|l|}{ Psychological well-being } \\
\hline \multirow{3}{*}{ Anxiety } & $\bar{x}$ & 1.60 & 1.65 & 1.57 & 1.59 \\
\hline & $S D$ & 0.64 & 0.79 & 0.59 & 0.63 \\
\hline & Skewness & 1.54 & 1.80 & 1.69 & 1.74 \\
\hline \multirow[t]{3}{*}{ Depression } & $\bar{x}$ & 1.66 & 1.68 & 1.64 & 1.64 \\
\hline & $S D$ & 0.69 & 0.63 & 0.71 & 0.70 \\
\hline & Skewness & 1.61 & 0.96 & 1.72 & 1.62 \\
\hline \multirow[t]{3}{*}{ Self-acceptance } & $\bar{x}$ & 4.48 & 4.65 & 4.51 & 4.52 \\
\hline & $S D$ & 0.77 & 0.56 & 0.71 & 0.70 \\
\hline & Skewness & -2.13 & -1.92 & -1.91 & -1.97 \\
\hline \multirow[t]{3}{*}{ Active coping } & $\bar{x}$ & 4.26 & 4.15 & 4.19 & 4.19 \\
\hline & $S D$ & 0.56 & 0.56 & 0.58 & 0.57 \\
\hline & Skewness & -0.93 & -0.53 & -0.81 & -0.78 \\
\hline \multicolumn{6}{|l|}{ Social support } \\
\hline \multirow[t]{3}{*}{ Friend support } & $\bar{x}$ & 2.99 & 3.08 & 3.18 & 3.14 \\
\hline & $S D$ & 1.03 & 0.86 & 0.98 & 0.97 \\
\hline & Skewness & 0.05 & 0.15 & -0.28 & -0.19 \\
\hline \multirow[t]{3}{*}{ Parent support } & $\bar{x}$ & 3.83 & 3.96 & 4.01 & 3.98 \\
\hline & $S D$ & 1.13 & 1.07 & 0.98 & 1.01 \\
\hline & Skewness & -1.01 & -1.28 & -1.05 & -1.09 \\
\hline \multirow[t]{3}{*}{ Time with mother } & $\bar{x}$ & 3.94 & 3.84 & 3.90 & 3.89 \\
\hline & $S D$ & 1.60 & 1.60 & 1.49 & 1.52 \\
\hline & Skewness & -0.05 & -0.05 & 0.05 & -0.03 \\
\hline \multirow[t]{3}{*}{ Time with father } & $\bar{x}$ & 2.22 & 2.05 & 2.51 & 2.42 \\
\hline & $S D$ & 1.42 & 1.35 & 1.51 & 1.49 \\
\hline & Skewness & 1.12 & 1.51 & 0.81 & 0.92 \\
\hline \multicolumn{6}{|l|}{ School outcomes } \\
\hline \multirow[t]{3}{*}{ School bonding } & $\bar{x}$ & 2.93 & 2.78 & 2.82 & 2.83 \\
\hline & $S D$ & 0.68 & 0.62 & 0.63 & 0.64 \\
\hline & Skewness & -0.48 & -0.23 & -0.12 & -0.17 \\
\hline \multirow[t]{3}{*}{ Skipping days } & $\bar{x}$ & 1.75 & 1.68 & 1.64 & 1.66 \\
\hline & $S D$ & 1.32 & 1.52 & 1.31 & 1.34 \\
\hline & Skewness & 1.77 & 2.37 & 2.20 & 2.18 \\
\hline \multirow[t]{3}{*}{ Graduating high school } & $\bar{x}$ & 4.52 & 4.55 & 4.66 & 4.63 \\
\hline & $S D$ & 0.87 & 0.83 & 0.70 & 0.74 \\
\hline & Skewness & -2.00 & -2.03 & -1.84 & -1.93 \\
\hline \multirow[t]{3}{*}{ Grade point average (GPA) } & $\bar{x}$ & 1.88 & 2.02 & 2.05 & 2.03 \\
\hline & $S D$ & 0.73 & 0.67 & 0.68 & 0.69 \\
\hline & Skewness & -0.48 & -0.40 & -0.47 & -0.47 \\
\hline
\end{tabular}


Table V. Descriptive Statistics for Sexual Behaviors Across Groups and Total Sample for Study 2

\begin{tabular}{clrrrr}
\hline & & $\begin{array}{r}\leq 17 \\
(n=45)\end{array}$ & $\begin{array}{c}18-19 \\
(n=49)\end{array}$ & $\begin{array}{c}\geq 20 \\
(n=239)\end{array}$ & $\begin{array}{c}\text { Total } \\
(n=333)\end{array}$ \\
\hline Sexual behavior & $\bar{x}$ & 12.87 & 12.39 & 12.25 & 12.36 \\
Age of initiation & $S D$ & 1.77 & 2.00 & 2.01 & 1.98 \\
& Skewness & -0.98 & -1.63 & -1.53 & -1.48 \\
Frequency of sexual & $\bar{x}$ & 2.80 & 3.00 & 2.77 & 2.81 \\
intercourse & $S D$ & 1.50 & 1.46 & 1.47 & 1.47 \\
Number of partners & Skewness & 0.27 & 0.04 & 0.36 & 0.30 \\
& $\bar{x}$ & 3.04 & 4.49 & 3.41 & 3.52 \\
Birth control & $S D$ & 2.50 & 4.41 & 3.24 & 3.37 \\
& Skewness & 1.43 & 1.97 & 2.39 & 2.34 \\
& $\bar{x}$ & 16.90 & 16.09 & 15.90 & 16.06 \\
& $S D$ & 2.88 & 2.58 & 2.62 & 2.67 \\
& Skewness & -0.26 & -0.22 & -0.25 & -0.21 \\
\hline
\end{tabular}

Bentler, 1986). Students were asked to choose from statements exactly opposite from each other ( 1 - first statement true; 5 - second statement true) concerning whether they were happy or unhappy with themselves, discouraged or pleased with themselves, liked or disliked themselves, and regarded themselves as a failure or success. In this sample the standardized Cronbach alpha coefficient for the self-acceptance scale was .66. The 8-item active coping measure assesses one's beliefs about hard work and achievement. It uses a 3-point Likert scale. This measure has been used in comparative studies of race and hypertension (James, Strogatz, Wing, \& Ramsey, 1987). The Cronbach alpha is .71 in this sample.

Social Support. The social support measures used the same scales of parent and friend support as used in Study 1, but the scales were further shortened. Each scale included five items. The parent support scale has a Cronbach alpha of .89. The friend support scale has a Cronbach alpha of .83. Time spent with both parents was also included. Youths were asked to report the amount of time they spent with their mother and father in shared activities. Each item used a 6-point scale ranging from 1 (no time) to 6 (16 or more hours).

School Outcomes. School outcomes included school records of youths' grade-point average (GPA) in eighth grade, skipping school, likelihood of graduating from high school, and attitudes about school. Students were asked to report the number of whole days of school missed in the last 4 weeks because they skipped or cut days $(1-$ none; $7-11+)$. Youths were asked to indicate how likely it is that they will graduate from high school $(1-$ not at all likely; 5 - very likely). School attitudes were assessed through a 7-item 
school bonding measure that used a 4-point Likert scale (Hawkins et al., 1992). Representative items include "I do extra work on my own in class; I like my English teacher this year; Most mornings, I look forward to going to school." The school bonding measure has a Cronbach alpha of .70 in this sample.

Sexual Behavior. Youths were asked if they ever had sexual intercourse. Among those youths who reported sexual activity $(n=333 ; 58 \%)$, a series of sexual behavior questions were asked including (1) frequency of birth control use; (2) age at initiation of sexual activity; (3) number of sexual partners; and (4) frequency of sexual intercourse. Frequency of birth control was measured with a 4-item scale measuring reported use of birth control during intercourse. Students were asked if they used a condom the first time they had sexual intercourse (yes/no); if they used another kind of birth control the first time they had sexual intercourse (yes/no); how often they have used a condom during sexual intercourse (1 - almost never; 5 - always); and how often they use another kind of birth control during sexual intercourse (1 almost never; 5 - always). Scores were standardized and summed. Youths were also asked to report how old they were the first time they had sexual intercourse and how many sex partners they have had in their lifetime. Frequency of sexual intercourse was measured with a single item asking students to report the number of times they have had sexual intercourse in their lives (1-1-2 times; $5-12$ or more times). Only youths who reported having sexual intercourse were included in the sexual behavior MANOVA. Youths were also asked if they had any children. Twenty youths had missing data on their sexual behaviors.

\section{Results}

\section{Attrition Analyses}

The first set of analyses examined the youths who were dropped from the analyses of maternal age because of missing data and those included. Youths in the study reported more parental support than those dropped, $\bar{x}=3.98$ vs. $3.72 ; t(141.5)=-2.24 ; p<.05$, friend support, $\bar{x}=3.15$ vs. $2.90 ; t(673)=$ $-2.45 ; p<.05$, and time with mother, $\bar{x}=3.86$ vs. $3.26 ; t(673)=-3.42$; $p<.01$. Youths in the study also reported less time with father $(\bar{x}=2.42)$ than youths dropped from the study, $\bar{x}=3.06 ; t(125.7)=3.22 ; p<.01$. No other differences were found for mother's education, problem behaviors, psychological well-being, school outcomes, or sexual behaviors. Males and females were equally likely to be dropped from the study $\chi^{2}(1)=.093 ; n s$. 


\section{Mother's Education}

Differences were found across the three mother's age groups for mother's education, $F(2,566)=4.86 ; p<.01$. Duncan paired comparison tests indicated that the 20-year-old and older mothers had more education (3.89) than the 17-year-old and younger mothers (3.18). Mother's education was associated with their adolescents' depression $(r=-.13 ; p<.05)$, likelihood of graduating from high school $(r=.15 ; p<.05)$, and age of first sexual intercourse $(r=-.12 ; p<.05)$, but was not correlated with any other psychosocial outcome of their children.

\section{Multivariate Analysis}

Separate MANOVA were computed for the five sets of psychosocial variables - problem behaviors, psychological well-being, social support, school outcomes, and sexual behavior. No differences were found across the three groups for problem behaviors, $F(8,1094)=1.50 ; n s$, psychological well-being, $F(8,1118)=.93$; $n s$, social support, $F(8,1050)=1.58 ; n s$, or school outcomes, $F(8,1122)=1.09 ; n s$. Sexual behaviors did differ across groups, $F(8,624=2.45 ; p<.05$. Univariate tests indicated that only number of sexual partners differed across groups, $F(2,331)=4.61 ; p<.05$. Duncan paired comparisons indicated that youth in the 18-19 year-old mother group reported more sexual partners (5.0) than either the 17 and younger group (3.0) or the 20 and older group (3.4).

Comparisons of youth outcomes for groups defined by mother's age over 20 versus under 20 were the same as the three-group analysis. We also repeated all the MANOVA analyses described earlier, using mother's education as a covariate and the results remained the same.

\section{Interviewer Effects}

We found no differences on any outcome for the interviewer race. The only interviewer sex effects found were for active coping, $t(675)=-2.21$; $p<.05$, and shared activities with mother, $t(669)=-2.04 ; p<.05$. Youth interviewed by males reported less active coping $(\bar{x}=4.12 ; S D=.59)$ than youth interviewed by females $(\bar{x}=4.22 ; S D=.55)$. Youth interviewed by males reported less time with mother $(\bar{x}=3.65 ; S D=1.56)$ than youth interviewed by females $(\bar{x}=3.90 ; S D=1.59)$. No other sex effects for interviewer were found. 


\section{DISCUSSION}

The results from two separate samples of adolescents indicate no psychosocial or substance use differences for the adolescent offspring of young teen mothers ( 17 years old or younger), late teen mothers (18-19 years old) or nonteen mothers (20 years and older). These results are largely consistent with previous research. Furstenberg (1992) found that most of the youths born to teen mothers did not have deleterious outcomes, despite early disadvantages. East and Felice (1990) also found that teenage motherhood does not necessarily result in deleterious outcomes as their children grow through adolescence. The only behavioral difference found across groups was that youths whose mothers were 18-19 years old when they were born had more sexual partners than youths with younger or older mothers at birth. This finding, however, did not directly contradict our hypothesis of no teen mother effects because adolescents with the youngest mothers were more similar to adolescents with older mothers on this variable. It is also noteworthy that none of the other sexual behavior variables (i.e., birth control use, age of initiation, frequency of sexual intercourse) differed across groups. Additionally, the sexual behavior outcomes were based on only the sexually active youth in Study 2.

Overall the results suggest that maternal age at birth is not related to negative developmental outcomes among low school achieving, urban, African American adolescents. These youths were neither more nor less likely to report negative outcomes because their mother was under 20 years or older. Our confidence in the results are further strengthened by replication across two samples after mother's education was also taken into account. The results may have several explanations. First, it is possible that other factors may be more relevant for adolescent outcomes than mother's age when they were born. Family relationships (Chatters, Taylor, \& Jayakody, 1994; Salem, Zimmerman, \& Notaro, 1998; Stice, Barrera, \& Chassin, 1993; Zimmerman, Salem, \& Maton, 1995; Zimmerman, Salem, \& Notaro, 2000; Zimmerman, Steinman, \& Rowe, 1998) and parenting style (Baumrind, 1991; Steinberg, Lamborn, Darling, Mounts, \& Dornbusch, 1994) may be more relevant for adolescent development than age of mother at birth. Second, teen mothers may work hard to make certain their children are not disadvantaged as compared to mothers who have children later in life. It is also possible that many teen mothers obtain the support they need in order to have similar parenting resources as mothers who give birth when they are older (Geronimus, 1992; McAdoo, 1988). Health and social service programs for teen mothers may also be providing the support and resources needed for them to do as well in raising their children as older mothers. It is noteworthy that our parental support results (i.e., no group differences) suggest that age of 
mother at birth does not adversely affect the level of support youth perceive during adolescence. Third, older mothers in the communities studied may not be relatively advantaged when compared to teens. Or in other words, teen mothers may not have been more disadvantaged than older mothers in these communities. Thus, the resources and support teen mothers receive may influence the type of outcomes their children experience in adolescence. Our results do suggest that teen mothers have lower educational levels than older mothers, but these differences had no effect on outcomes for the adolescent children in our studies. Finally, it is conceivable that teen mothers, even though socioeconomically disadvantaged (as by their education), can raise their children to be relatively healthy, well-functioning adolescents.

Family process (e.g., parental support, parenting style) may be more predictive of adolescent outcomes than maternal age. Hubbs-Tait et al. (1994) found, for example, that mother-infant attachment, maternal depression, and maternal self-esteem were associated with child behavior problems and social competence among teen mothers. Cooley and Unger (1991) found that family support was indirectly related to maternal educational attainment and effective parenting skills. Similarly, our results indicated that parental support and time with parents in both studies did not differ by maternal age. Salem et al. (1998) found that parental support was associated with adolescent outcomes, and that the effects of father involvement were mediated by parental support in predicting outcomes (e.g., problem behavior, psychological well-being). Zimmerman et al. (1998) also found that parental support protected youths from risks associated with violent behavior such as friends' and nonfamily adult violent behavior. Barratt (1991) found that among teen mothers, higher maternal education and intelligence were associated with child educational achievement. Regardless of the mother's childbearing age, parenting styles have consistently been linked to adolescent problem behaviors and prosocial behaviors (Baumrind, 1991; Lamborn, Mounts, Steinberg, \& Dornbusch, 1991; Maccoby \& Martin, 1983; Small \& Eastman, 1991; Steinberg, Elmen, \& Mounts, 1989; Steinberg, Mounts, Lamborn, \& Dornbusch, 1991; Stice et al., 1993).

Olds and colleagues describe a home visitation intervention designed to enhance the parenting skills of teenage mothers (Olds et al., 1998; Olds \& Korfmacher, 1997). Although their intervention was not exclusively for teen mothers, their sample included 151 mothers under 18. The intervention included nurse home visitation both prenatally and for 2 years after the birth of the first child. The visits included teaching mothers about positive health behaviors, the competent care of their child, family planning, educational achievement, participation in the workforce, and strategies for obtaining support from family and friends. They examined the outcomes for the children 15 years after they were born. Olds et al. (1998) found that the 
adolescent children of mothers who were home visited were less likely to engage in antisocial behavior (e.g., runaway, criminal activity, cigarette and alcohol use) than youths whose mothers were not in the program. They also found the adolescent children whose mothers were in the program reported fewer sexual partners and less behavior problems associated with alcohol and drug use than their counterparts whose mothers did not participate in the program. This type of intervention may be a promising strategy to ensure the healthy development of children of teenage parents.

Nevertheless, parenting practices alone may provide only limited insights about adolescent development or how to ensure healthy outcomes. Research that focuses only on family context may unintentionally blame the families for negative adolescent outcomes while neglecting social structural barriers to healthy development. Although researchers have found that parenting practices, maternal self-esteem and education, and home environment may be more predictive of outcomes than maternal age is, few investigators who examine the role of parenting have also examined the role that social structural characteristics such as social capital, institutional racism, or accessibility of resources may play in adolescent development. Future research that takes these issues into account may provide further evidence that maternal age in particular, and family environment more generally, may have less overall effect on urban, African American, low achieving adolescent development than do social structural variables.

Racial identity may also be more significant for adolescent development than maternal age is. Several researchers have found that negative racial or ethnic identity is associated with problem behaviors (Rotherman-Borus, 1989), decreased self-esteem and mental health (Arroyo \& Zigler, 1995; Munford, 1994; Rowley, Sellers, Chavous, \& Smith, 1998), and lower academic achievement (Witherspoon, Speight, \& Thomas, 1997). Martinez and Dukes (1997), for example, found that youth with lower salience of ethnic identity, regardless of race, had lower self-esteem, less self-confidence, and less purpose in life. Future research that examines racial identity and salience as it relates to family processes such as support and parenting practices may provide more insight into adolescent development than family factors alone. Racial identity may be especially meaningful to study for low achieving youth because of its association with academic outcomes (Witherspoon et al., 1997).

Several limitations of the study should be noted. The most central concern is that we used youths' self-reports of their mothers' ages to define our independent variable groupings. We think our groupings are a valid measure for several reasons. First, a study of 80 high school students found that adolescents' self-reports of their mothers' ages are consistent with their mothers' reports of their ages (Zimmerman, Rowe, Tuttle, \& Bryant, 1997). They found that $70 \%$ of the youths reported the same ages as their mothers, 
and that $95 \%$ of the youths were within 1 year of their mothers' reports. Second, the rates of teen births among African American women for the years covered in our two samples (1970 for Study 1, and 1980 for Study 2) also suggest that the youths may have accurately reported their mothers' ages. In 1970, 34.2\% of all births to African American mothers in Maryland were among teens (19 or younger). In 1980 for Michigan, $24.7 \%$ of all births to African American mothers were among teens, 19 or younger (U.S. Department of Commerce, Bureau of Census, 1996). Our rates of teen mothers were $37.5 \%$ in the Maryland sample (Study 1) and $25.4 \%$ in the Michigan sample (Study 2). Finally, the fact that we found similar results in two different samples, and that these results are consistent with those of others who have examined similar questions, adds to our confidence that youths accurately reported their mother's age.

Another limitation of the studies is that the sample included only low achieving, urban, African American youths and may not be generalizable to other adolescent populations. The rate of teen births, however, is high among African American adolescents so it is particularly vital to study this population. It is also quite possible that being born to a teen mother may have differential effects for different racial and ethnic groups. Thus, including only African American youths is a strength of the study, because we do not make inappropriate comparisons to White samples nor do we combine different racial/ethnic groups into one sample. The diversity of experiences identified by within-group analyses allows us to focus programs and policy on subgroups of youth that may be especially vulnerable to the risks they face.

The fact that students in Study 1 were selected based on their school attendance, and in Study 2 on a GPA of 3.0 or lower, also limits the generalizability of the results. The results, therefore, may not be applicable to youths who are more successful in school. Yet, low achieving youth may also be a critical group to study because they are at increased risk for negative outcomes. School performance is associated with many negative outcomes such as school dropout, alcohol and substance use, lower earning potential, and health compromising behavior. Studying youth who are at increased risk for negative outcomes may also help provide valuable insights into the accumulation of risk factors and the role of protective factors (Zimmerman \& Arunkumar, 1994).

An additional implication of including only low school achieving youths may be that this, and not their mother's age, accounts for any negative effects of being the offspring of a teen mother. Yet, several issues suggest that their achievement status alone does explain the results. First, the descriptive statistics of the dependent variables suggest they have sufficient variance and are not widely skewed (e.g., most have skewness under 1.0). It is also notable that 
we have found many theoretically consistent relationships among variables within these samples, further suggesting that the variables in the study have enough variance for explaining relevant variables (Doljanac \& Zimmerman, 1998; Ramirez-Valles, Zimmerman, \& Newcomb, 1998; Salem et al., 1998; Zimmerman et al., 1995; 2000). Thus, the reasoning that the distribution of these variables may be truncated because of the nature of the sample, and therefore, restricted range of the variables explains the lack of findings, is not supported by the data. Second, our results were replicated in two samples, one of which was more highly achieving than the other. In Study 2 half of the students had average or above average grades, and only the most highly achieving students were not sampled. Third, we had a large enough sample in Study 2 for adequate statistical power to detect small effects. Consequently, even if the variance was limited by the sample selection criteria, we had ample statistical power to avoid a Type II error (i.e., false negative conclusion). In addition, we had a large enough sample in Study 1 to detect moderate to small effects.

The sample characteristics in our two studies, however, may be viewed as a strength of the research because they provide a unique opportunity to test hypotheses among youth often associated with many urban problems. Although it is true that the low achieving nature of our samples may not allow for generalizability to other African American youths, these youths are a critical group to study. Urban African American youths, especially males, are precisely those Gibbs (1984) suggests are "least recognized and least effectively addressed in terms of research, policy formation and service programs" (p. 12). Many public policies to address youths like the ones in our studies are based in part on assumptions about teen motherhood. These two studies may help enhance our understanding of a unique, but significant population. It is also noteworthy that not all low school achieving youths are the same, as significant numbers of them do not engage in problem behavior, feel badly about themselves or their lives, or fail to participate in schoolrelated activities (Fine, 1983; Maton \& Zimmerman, 1992; Zimmerman et al., 2000).

The attrition and interviewer effect analyses eliminate these alternative explanations of the results. The absence of systematic attrition effects in Study 2 suggest that the results are not explained by the fact that the most distressed youths were eliminated from the study because they did not report their mother's age. Although differences were found for the social support variables, it is noteworthy that they did not differ on any other outcome. It is especially notable that mother's educational level did not differ between youths included and dropped from the analyses. Yet, the fact that the support variables did differ may provide some explanation for why the youths dropped from the analysis may not have known their mother's age. 
Youths who spend less time with their mothers and report less support from parents did not know their mother's age. It is logical that these two variables would be correlated. Similarly, the youths who were dropped from the study reported spending more time with their fathers. This is also consistent with the idea that they may be less aware of and involved with their mothers and, therefore, may not know her age. Overall, however, the attrition analyses eliminate an alternative explanation of the results. Similarly, the very limited findings of interviewer race and sex effects indicate these factors can also be ruled out as alternative explanations.

Another limitation of the research is that it included only self-report data. This may be especially problematic for questions involving illicit behavior such as delinquency, and alcohol and drug use. Although these measures had adequate internal consistency as measured by Cronbach's alpha, the validity of the self-reports may be questioned. Several issues enhance our confidence that these data are as accurate as those of other researchers measuring similar behaviors. The alcohol and drug use, and sexual behavior data gathered in Study 2 were collected by a self-administered questionnaire at the end of the face-to-face interview. This somewhat mitigates the concern that interviewing may bias the responses to sensitive questions. In addition, the lack of interviewer effects for these questions (only alcohol use in Study 1 differed by interviewer race or sex) further mitigates concerns about interviewer bias. Our results are also similar to national samples. The alcohol use rate in our sample, for example, was 58\% compared to $60 \%$ of African Americans in the nationally representative 1997 Monitoring the Future study (Johnston, O'Malley, \& Bachman, 1998).

The relevance of the measures used for African American youth may also be questioned. We did not select instruments specifically designed for African American populations, but many of the measures have been used with samples of African Americans in the past (e.g., Rosenberg's self-esteem measure). The reliability estimates based on the samples studied were all quite high indicating at least that the respondents answered consistently to the items. It is possible that we may have found some effects of mother's age on offspring if we included culturally specific measures. Yet, this issue may be most applicable for the attitudinal variables (e.g., life satisfaction, school bonding), but less relevant for measures of behaviors (e.g., alcohol and drug use, delinquency, violent behavior, sex behavior) or school variables (e.g., grade point average, school days skipped). It is also notable that our measure of active coping in Study 2 was developed for African American samples by a researcher of African descent. In fact, the measure was named the John Henryism scale after the African American folk hero (James et al., 1987).

It is critical to point out that the results of these studies should not be interpreted to suggest that teen pregnancy prevention programs in African 
American communities are unnecessary. Many investigators have identified several potentially negative consequences of early childbearing on the adolescent parent (Furstenberg, Brooks-Gunn, \& Morgan, 1987; Hetchman, 1989; McAnarney \& Hendee, 1989; Scholl et al., 1994; Scholl \& Hediger, 1993; Spivak \& Weitzman, 1987). Programs to help prevent teenage parenthood are critical to help the adolescent parent avoid the adverse health, educational, social, and economic consequences that are often associated with early childbearing. The results of this study and others, however, suggest that it may be useful if these programs focus more attention on the consequences for teen parents than do their children. Nevertheless, efforts to insure the healthy development of children regardless of the age of their mother may be beneficial (Olds et al., 1998; Olds \& Korfmacher, 1997). It may also be useful for teen pregnancy prevention programs to be part of a larger prevention strategy that incorporates social structural change efforts and does not focus only on individual level change.

These two studies add to the limited number of analyses that examine adolescent outcomes for children of teen mothers. We have replicated some previous findings and expanded the number of outcomes studied. The results of these studies and others suggest that being born to teen mothers does not predict outcomes for their adolescent children. The sexual behavior results also suggest that the notion that teen mothers have children who are more likely than those of adult mothers to become teen mothers themselves may not be correct. Research may be more useful and productive if we consider how mother and child relationships, parenting behavior, and family functioning may directly affect outcomes for adolescents born to teen mothers. Family processes may help protect youths who are both socioeconomically disadvantaged and born to teen mothers. It may also be worthwhile to study how fathers of teen mothers' offspring may influence adolescent outcomes rather than focusing all the attention on mothers (Caldwell \& Antonucci, 1997). Finally, more efforts to understand social structural determinants of healthy and problematic adolescent development including community and other support systems, racism, and social class may be most informative.

\section{REFERENCES}

Alexander, C. S. R. M. P., \& Guyer, B. M. M. (1993). Adolescent pregnancy: Occurrence and consequences. Pediatric Annals, 22(2), 85-88.

Arroyo, C. G., \& Zigler, E. (1995). Racial identity, academic achievement, and the psychological well-being of economically disadvantaged adolescents. Journal of Personality and Social Psychology, 69, 903-914.

Bachman, J. G., Wadsworth, K. N., O’Malley, P. M., Schulenberg, J., \& Johnston, L. D. (1997). Marriage, divorce, and parenthood during the transition to young adulthood: Impacts on 
drug use and abuse. In J. Schulenberg, J. L. Maggs, \& K. Hurrelmann (Eds.), Health risks and developmental transitions during adolescence (pp. 246-279). New York: Cambridge University Press.

Bachrach, C. A., Clogg, C. C., \& Carver, K. (1993). Outcomes of early childbearing: Summary of a conference. Journal of Research on Adolescence, 3(4), 337-348.

Baldwin, W. (1993). The consequences of early childbearing: A perspective. Journal of Research on Adolescence, 3(4), 349-352.

Baldwin, W., \& Cain, V. S. (1980). The children of teenage parents. Family Planning Perspectives, 12(1), 34-43.

Barratt, M. S. (1991). School-age offspring of adolescent mothers: Environments and outcomes. Family Relations, 40, 442-447.

Baumrind, D. (1991). The influence of parenting style on adolescent competence and substance use. Journal of Early Adolescence, 11(1), 56-95.

Brooks-Gunn, J., \& Chase-Lansdale, P. L. (1995). Adolescent parenthood. In M. Bornstein (Ed.), Handbook of parenting: Vol. 3. Status and social conditions of parenting (pp. 113149). Mahwah, NJ: Erlbaum.

Brooks-Gunn, J., Guo, G., \& Furstenberg, F. F. J. (1993). Who drops out of and who continues beyond high school? A 20-year follow-up of Black urban youth. Journal of Research on Adolescence, 3(3), 271-294.

Buchholz, E. S., \& Gol, B. (1986). More than playing house: A developmental perspective on the strengths in teenage motherhood. American Journal of Orthopsychiatry, 56(3), 347359.

Caldwell, C. H., \& Antonucci, T. C. (1997). Childbearing during adolescence: Mental health risks and opportunities. In J. Schulenberg, J. L. Maggs, \& K. Hurrelmann (Eds.), Health risks and developmental transitions during adolescence (pp. 220-245). UK: Cambridge University Press.

Camp, B. W. (1996). Adolescent mothers and their children: Changes in maternal characteristics and child developmental and behavioral outcome at school age. Journal of Developmental and Behavioral Pediatrics, 17, 162-169.

Chase-Lansdale, P. L., Mott, F. L., Brooks-Gunn, J., \& Phillips, D. A. (1991). Children of the National Longitudinal Survey of Youth: A unique research opportunity. Developmental Psychology, 27(6), 918-931.

Chatters, L. M., Taylor, R. J., \& Jayakody, R. (1994). Fictive kinship relations in Black extended families. Journal of Comparative Family Studies, 25, 297-313.

Cooley, M. L., \& Unger, D. G. (1991). The role of family support in determining developmental outcomes in children of teen mothers. Child Psychiatry and Human Development, 21(3), 217-234.

Derogatis, L. R., \& Spencer, P. M. (1982). The brief symptom inventory (BSI): Administration, scoring and procedures manual $-I$. Baltimore, MD: Division of Medical Psychology, Johns Hopkins University School of Medicine.

Diener, E., Emmons, R. A., Larsen, R. J., \& Griffin, S. (1985). The satisfaction with life scale. Journal of Personality Assessment, 49, 71-75.

Doljanac, R. F., \& Zimmerman, M. A. (1998). Psychosocial factors and high-risk sexual behavior: Race differences among urban adolescents. Journal of Behavioral Medicine, 21, 451-467.

Dubow, E. F., \& Luster, T. (1990). Adjustment of children born to teenage mothers: The contribution of risk and protective factors. Journal of Marriage and the Family, 52, 393-404.

East, P. L., \& Felice, M. E. (1990). Outcomes and parent-child relationships of former adolescent mothers and their 12-year-old children. Developmental and Behavioral Pediatrics, 11(4), $175-183$.

Fergusson, D. M., \& Woodward, L. J. (1999). Maternal age and educational and psychosocial outcomes in early adulthood. Journal of Child Psychology and Psychiatry and Allied Disciplines, 40, 479-489.

Fine, M. (1983). Perspectives on inequity: Voice from urban schools. Applied Social Psychology Annual, 4, 217-246. 
Furstenberg, F. F. (1992). Teenage childbearing and cultural rationality: A thesis in search of evidence. Family Relations, 41, 239-243.

Furstenberg, F. F., Brooks-Gunn, J., \& Morgan, S. P. (1987). Adolescent mothers and their children in later life. Family Planning Perspectives, 19(4), 142-151.

Furstenberg, F. F., \& Harris, K. M. (1993). When fathers matter/why fathers matter: The impact of paternal involvement on the offspring of adolescent mothers. In The politics of pregnancy (pp. 189-215). New Haven, CT: Yale University Press.

Furstenberg, F. F., Hughes, M. E., \& Brooks-Gunn, J. (1993). The next generation: The children of teenage mothers grow up. In Early parenthood and the coming of age in the 1990s (pp. 113-135). New Brunswick, NJ: Rutgers University Press.

Geronimus, A. T. (1992). The weathering hypothesis and the health of African American women and infants: Evidence and speculations. Ethnicity and Disease, 2, 207-221.

Geronimus, A. T. (1996). Black/white differences in the relationship of maternal age to birthweight: A population-based test of the weathering hypothesis. Social Science and Medicine, 42, 589-597.

Geronimus, A. T., Korenman, S., \& Hillemeier, M. M. (1994). Does young maternal age adversely affect child development? Evidence from cousin comparisons in the United States. Population and Development Review, 20(3), 585-609.

Gibbs, J. T. (1984). Black adolescents and youth: An endangered species. American Journal of Orthopsychiatry, 54, 6-21.

Hardy, J. B., Astone, N. M., Brooks-Gunn, J., Shapiro, S., \& Miller, T. L. (1998). Like mother, like child: Intergenerational patterns of age at first birth and associations with childhood and adolescent characteristics and adult outcomes in the second generation. Developmental Psychology, 34, 1220-1232.

Hawkins, J. D., Catalano, R. F., Morrison, D. M., O’Donnell, J., Abbott, R. D., \& Day, L. E. (1992). The Seattle Social Development Project: Effects of the first four years on protective factors and problem behaviors. In J. McCord \& R. Tremblay (Eds.), Preventing antisocial behavior: Interventions from birth through adolescence (pp. 139-161). New York: Guilford Press.

Hetchman, L. (1989). Teenage mothers and their children: Risks and problems. A review. Canadian Journal of Psychiatry, 34, 569-575.

Hofferth, S. (1987). The children of teen childbearers. In S. Hofferth \& C. Hayes (Eds.), Risking the future: Adolescent sexuality, pregnancy and childbearing (Volume 1). Washington, DC: National Academy Press.

Hubbs-Tait, L., Osofsky, J. D., Hann, D. M., \& Culp, A. M. (1994). Predicting behavior problems and social competence in children of adolescent mothers. Family Relations, 43, 439-446.

James, S. A., Strogatz, D. S., Wing, S. B., \& Ramsey, D. L. (1987). Socioeconomic status, John Henryism, and hypertension in Blacks and Whites. American Journal of Epidemiology, 126, 664-673.

Johnston, L. D., O’Malley, P. M., \& Bachman, J. G. (1998). National survey results on drug use: Vol. 1. Secondary school students. Ann Arbor, MI: Institute of Social Research, University of Michigan.

Ketterlinus, R. D., Henderson, S., \& Lamb, M. E. (1991). The effects of maternal age-at-birth on children's cognitive development. Journal of Research on Adolescence, 1(2), 173-188.

Kieffer, E., Alexander, G., \& Mor, J. (1995). Pregnancy outcomes of Pacific Islanders in Hawaii. American Journal of Epidemiology, 141, 674-679.

Kieffer, E., Mor, J., \& Alexander, G. (1996). Native Hawaiian birth weight and infant mortality: Is birth in Hawaii protective? Asian American and Pacific Islander Journal of Health, 4(4), 343-351.

Lamborn, S. D., Mounts, N. S., Steinberg, L., \& Dornbusch, S. M. (1991). Patterns of competence and adjustment among adolescents from authoritative, authoritarian, indulgent, and neglectful families. Child Development, 62, 1049-1065.

Luster, T., \& Dubow, E. (1990). Predictors of the quality of the home environment that adolescent mothers provide for their school-aged children. Journal of Youth and Adolescence, 19(5), 475-494. 
Maccoby, E. E., \& Martin, J. A. (1983). Socialization in the context of the family: Parent-child interaction. In E. M. Hetherington, \& P. H. Mussen (Eds.), Handbook of child psychology: Vol. 4. Socialization, personality and social development (pp. 1-101). New York: Wiley.

Martinez, R. O., \& Dukes, R. L. (1997). The effects of ethnic identity, ethnicity, and gender on adolescent well-being. Journal of Youth and Adolescence, 24, 377-396.

Maton, K. I., \& Zimmerman, M. A. (1992). Psychosocial predictors of substance use among urban Black male adolescents. Drugs and Society, 6, 79-113.

McAdoo, H. P. (1988). Black families. Newbury Park, CA: Sage.

McAnarney, E. R., \& Hendee, W. R. (1989). Adolescent pregnancy and its consequences. JAMA, 262(1), 74-77.

Munford, M. B. (1994). Relationship of gender, self-esteem, social class, and racial identity to depression in blacks. Journal of Black Psychology, 20, 157-174.

National Research Council. (1987). Risking the future: Adolescent sexuality, pregnancy and childbearing, (Vol. 1). Washington, DC: National Academy Press.

Olds, D., Henderson, C. R., Cole, R., Eckenrode, J., Kitzman, H., Luckey, D., Pettit, L., Sidora, K., Morris, P., \& Powers, J. (1998). Long-term effects of nurse home visitation on children's criminal and antisocial behavior: Fifteen-year follow-up of a randomized controlled trial. JAMA, 280, 1238-1244.

Olds, D., \& Korfmacher, J. (Eds.). (1997). Home visitation I. [Special issue]. Journal of Community Psychology, 25(1), 1-7.

Panzarine, S. (1988). Teen mothering: Behaviors and interventions. Journal of Adolescent Health Care, 9, 443-448.

Procidano, M. E., \& Heller, K. (1983). Measures of perceived social support from friends and from family: Three validation studies. American Journal of Community Psychology, 11, $1-24$.

Ramirez-Valles, J., Zimmerman, M. A., \& Newcomb, M. D. (1998). Sexual risk behavior among youth: Modeling the influence of prosocial activities and socioeconomic factors. Journal of Health and Social Behavior, 39, 237-253.

Rosenberg, M. (1979). Conceiving the self. New York: Basic Books.

Rotherman-Borus, M. J. (1989). Ethnic differences in adolescents' identity status and associated behavior problems. Journal of Adolescence, 12, 361-374.

Rowley, S. J., Sellers, R. M., Chavous, T. M., \& Smith, M. A. (1998). The relationship between racial identity and self-esteem in African American college and high school students. Journal of Personality and Social Psychology, 74, 715-724.

Salem, D. A., Zimmerman, M. A., \& Notaro, P. C. (1998). Effects of family structure, family process, and father involvement on psychosocial outcomes among African American adolescents. Family Relations, 47, 331-341.

Scholl T. O., \& Hediger, M. L. (1993). A review of the epidemiology of nutrition and adolescent pregnancy: Maternal growth during pregnancy and its effect on the fetus. Journal of the American College of Nutrition, 12(2), 101-107.

Scholl, T., Hediger, M. L., Schall, J. I., Khoo, C. S., \& Fischer, R. L. (1994). Maternal growth during pregnancy and the competition for nutrients. American Journal of Clinical Nutrition, 60, 183-188.

Small, S. A., \& Eastman, G. E. (1991). Rearing adolescents in contemporary society: A conceptual framework for understanding the responsibilities and needs of parents. Family Relations, 40, 455-462.

Spivak, H., \& Weitzman, M. (1987). Social barriers faced by adolescent parents and their children. JAMA, 258, 1500-1504.

Stein, J. A., Newcomb, M. D., \& Bentler P. M. (1986). Stability and change in personality: A longitudinal study from early adolescence to young adulthood. Journal of Research in Personality, 20, 276-291.

Steinberg, L., Elmen, J. D., \& Mounts, N. S. (1989). Authoritative parenting, psychosocial maturity, and academic success among adolescents. Child Development, 60, 1424-1436.

Steinberg, L., Lamborn, S. D., Darling, N., Mounts, N. S., \& Dornbusch, S. M. (1994). Overtime changes in adjustment and competence among adolescents from authoritative, 
authoritarian, indulgent, and neglectful families. Child Development, 65, 754770 .

Steinberg, L., Mounts, N. S., Lamborn, S. D., \& Dornbusch, S. M. (1991). Authoritative parenting and adolescent adjustment across varied ecological niches. Journal of Research on Adolescence, 1(1), 19-36.

Stice, E., Barrera, M., \& Chassin, L. (1993). Relation of parental support and control to adolescents' externalizing symptomatology and substance use: A longitudinal examination of curvilinear effects. Journal of Abnormal Child Psychology, 21(6), 609-629.

Witherspoon, K. M., Speight, S. L., \& Thomas, A. J. (1997). Racial identity attitudes, school achievement, and academic self-efficacy among African American high school students. Journal of Black Psychology, 23, 344-357.

Zimmerman, M. A., \& Arunkumar, R. (1994). Resiliency research: Implications for schools and policy. Social Policy Report, 8, 1-18.

Zimmerman, M. A., \& Maton, K. I. (1992). Lifestyle and substance use among urban Black male adolescents: A cluster analytic approach. American Journal of Community Psychology, 20, 121-138.

Zimmerman, M. A., Rowe, K., Tuttle, L., \& Bryant, A. (1997). Validity of adolescents' report of maternal age. American Journal of Community Psychology, 25, 887-891.

Zimmerman, M. A., Salem, D. A., \& Maton, K. I. (1995). Family structure and psychosocial correlates among urban African American adolescent males. Child Development, 66, 15981613.

Zimmerman, M. A., Salem, D. A., \& Notaro, P. C. (2000). Make room for daddy II: The positive effects of fathers' role in adolescent development. In R. Taylor \& M. Wang (Eds.), Resilience across contexts: Family, work, culture, and community (pp. 233-253). Mahwah, NJ: Erlbaum.

Zimmerman, M. A., Steinman, K., \& Rowe, K. (1998). Violence among urban African American adolescents: The protective effects of parental support. In X. B. Arriaga \& S. Oskamp (Eds.), Addressing community problems: Psychological research and intervention (pp. 78103). Thousand Oaks, CA: Sage. 